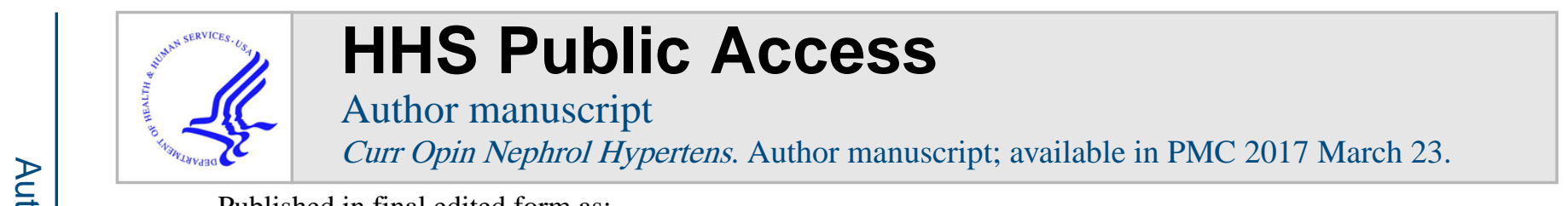

Published in final edited form as:

Curr Opin Nephrol Hypertens. 2015 September ; 24(5): 463-469. doi:10.1097/MNH.0000000000000152.

\title{
Sodium-glucose cotransport
}

\author{
Søren Brandt Poulsen ${ }^{\mathrm{a}, \mathrm{b}}$, Robert A. Fenton ${ }^{\mathrm{a}}$, and Timo Rieg ${ }^{\mathrm{b}, \mathrm{c}}$ \\ anterPrET Center, Department of Biomedicine, Aarhus University, Aarhus, Denmark \\ bVA San Diego Healthcare System, San Diego \\ 'Department of Medicine, University of California San Diego, La Jolla, California, USA
}

\begin{abstract}
Purpose of review-Sodium-glucose cotransporters (SGLTs) are important mediators of glucose uptake across apical cell membranes. SGLT1 mediates almost all sodium-dependent glucose uptake in the small intestine, while in the kidney SGLT2, and to a lesser extent SGLT1, account for more than $90 \%$ and nearly $3 \%$, respectively, of glucose reabsorption from the glomerular ultrafiltrate. Although the recent availability of SGLT2 inhibitors for the treatment of diabetes mellitus has increased the number of clinical studies, this review has a focus on mechanisms contributing to the cellular regulation of SGLTs.
\end{abstract}

Recent findings-Studies have focused on the regulation of SGLT expression under different physiological/pathophysiological conditions, for example diet, age or diabetes mellitus. Several studies provide evidence of SGLT regulation via cyclic adenosine monophosphate/protein kinase A, protein kinase C, glucagon-like peptide 2, insulin, leptin, signal transducer and activator of transcription-3 (STAT3), phosphoinositide-3 kinase (PI3K)/Akt, mitogen-activated protein kinases (MAPKs), nuclear factor-kappaB (NF-kappaB), with-no-K[Lys] kinases/STE20/SPS1-related proline/alanine-rich kinase (Wnk/SPAK) and regulatory solute carrier protein 1 (RS1) pathways.

Summary-SGLT inhibitors are important drugs for glycemic control in diabetes mellitus. Although the contribution of SGLT1 for absorption of glucose from the intestine as well as SGLT2/SGLT1 for renal glucose reabsorption has been comprehensively defined, this review provides an up-to-date outline for the mechanistic regulation of SGLT1/SGLT2.

\section{Keywords}

blood pressure; colon; dapagliflozin; diabetic nephropathy; glucagon-like peptide-1; phlorizin

\section{INTRODUCTION}

Sodium-glucose cotransporter (SGLT) activity mediates apical sodium and glucose transport across cell membranes. Cotransport is driven by active sodium extrusion by the basolateral

Correspondence to Dr Timo Rieg, Department of Medicine, Division of Nephrology-Hypertension, University of California San Diego \& VA San Diego Healthcare System, 3350 La Jolla Village Drive (9151), San Diego, CA 92161, USA. Tel: +1 8585528585 x5944; fax: +1 858642 1438; trieg@ ucsd.edu.

Conflicts of interest

There are no conflicts of interest. 
sodium/potassium-ATPase, thus facilitating glucose uptake against an intracellular up-hill gradient. Basolaterally, glucose exits the cell through facilitative glucose transporter 2 (GLUT2) [1]. In humans, six SGLT isoforms have been identified [2], but SGLT1 and SGLT2 are the focus of this review.

SGLT1 is responsible for glucose absorption in the small intestine [3"], and for reabsorbing nearly $3 \%$ of the filtered glucose load in the renal proximal tubule segment 3 (S3) [4"']. Until recently, tissue localization studies of SGLT1 were hampered by the lack of wellfunctioning antibodies [3",5]. In the intestine, examination of various species showed that SGLT1 is expressed in the luminal brush border of enterocytes [3",6-12], which are responsible for nutrient absorption, and in enteroendocrine L-cells and K-cells [3"], which produce the incretins glucagon-like peptide-1 (GLP-1) and glucose-dependent insulinotropic peptide (GIP) [1,13"']. SGLT1 knockout (Sglt1--) mice show glucose-gal-actose malabsorption and do not survive unless kept on a glucose-free diet [3"]. However, Sglt1-/mice have a comparable blood pressure compared with their wild-type littermates [3"].

SGLT2 is responsible for glucose reabsorption in the proximal tubule segment 1 and 2 $(\mathrm{S} 1 / 2)$ [5,13 $\mathbf{m}^{\mathbf{*}}$, wherein it reabsorbs more than $90 \%$ of the filtered glucose load [3",4"']. In SGLT2 knockout (Sglt2--) mice, however, SGLT1 may compensate and reabsorb up to 35\% of the filtered glucose load [14"]. Sodium homeostasis and blood pressure are unaffected in Sglt2-- mice [14"].

\section{KEY POINTS}

- $\quad$ SGLTs are regulated in a complex fashion; however, signaling pathways resulting in upregulation or downregulation are poorly defined.

- $\quad$ SGLT inhibitors may be efficient in the treatment of both type 1 and type 2 diabetes mellitus.

- Intestinal inhibition of SGLT1 may potentially improve glycemic control by delaying glucose absorption and by stabilizing GLP-1 blood plasma levels.

The human blood glucose concentration under normal conditions is nearly $5.5 \mathrm{mmol} / \mathrm{l}$, and less than $1 \%$ of filtered glucose is excreted in the urine [1,3 $]$. However, increasing amounts of glucose appear in the urine if blood levels exceed $10-12 \mathrm{mmol} / \mathrm{l}$, assuming that glomerular filtration rate is unaffected [1,2]. This may become evident in patients with insufficiently controlled diabetes mellitus. Under diabetic conditions, proximal tubule glucose reabsorption is enhanced via increased expression of SGLT2, possibly contributing to overt hyperglycemia $[1,2]$. The increased proximal tubule sodium reabsorption may reduce the downstream sodium and chloride concentration at the macula densa, thus activating the tubuloglomerular feedback mechanism. This may lead to early diabetic hyperfiltration and stimulation of the rennin-angiotensin-aldosterone system (RAAS) [15]. In patients living with diabetes mellitus for 10-20 years, approximately $20 \%$ develop diabetic nephropathy, which is currently the leading cause of end-stage renal disease [15]. 
This review focuses on the regulation of intestinal and renal SGLTs. The majority of studies presented in this review comprise investigations in cell cultures, isolated epithelia, purified membranes, isolated transport proteins or intact animals. Consequently, they reveal a rather complex regulatory pattern of SGLTs and may vary depending on experimental system or species studied. Each regulatory system may contribute to a different extent, resulting in differences in the overall final response.

\section{REGULATION OF SODIUM-GLUCOSE COTRANSPORTER 1}

Intestinal SGLT1 is modulated by dietary carbohydrate content. When rats, mice or sheep are fed a high-glucose diet, SGLT1 activity and expression are increased (for review see $[16,17])$. Interestingly, glucose seems to be a local mediator rather than a systemic mediator, as luminal but not intravenous administration of glucose increases intestinal SGLT1 expression in rats [18]. Along the same lines, obese mice show increased glucose transport as a result of increased mucosal mass with more SGLT1 transporters available, but this effect is independent of increased SGLT1 activity [19].

In addition, SGLT1 expression and activity exhibits a diurnal rhythm that correlates waking hours with highest expression of SGLT1 [20-23]. Of note, altering food intake may posttranslationally regulate the diurnal expression of SGLT1; however, the hormones or central/peripheral clock genes have not been identified so far [24]. As blood pressure also exhibits a diurnal rhythm, it is interesting that intestinal SGLT1 transport capacity and expression are significantly reduced in spontaneously hypertensive rats, although the mechanism is unclear [25]. Whether this is related to a general dysregulation of sodium transport is unknown; studies evaluating SGLT1 in salt-sensitive or salt-resistant models of hypertension deserve further consideration.

The signal(s) responsible for transcription and translation of SGLT1 mRNA, in addition to trafficking of SGLT1, are not well understood. A recent study identified that the cytoskeletal components a-tubulin and actin participate in the redistribution of SGLT1 [26",27]. In addition, when caveolin-1, a plasma membrane protein known to regulate the insertion and retrieval of transport proteins, and SGLT1 are coexpressed in oocytes, SGLT1 protein abundance and glucose transport increase [28]. However, these results need to be interpreted with caution because in vivo caveolin-1 protein, mRNA or immunofluorescence was undetectable in proximal tubules [29].

\section{Regulation by protein kinase $\mathrm{A}$ and protein kinase $\mathrm{C}$}

SGLT1 contains a number of consensus sites for regulation by protein kinase A (PKA) and protein kinase $\mathrm{C}$ (PKC), although the number of sites varies between species: one PKA site in rabbit and human, none in rat; five consensus PKC sites in rat and human and four in rabbit [30,31]. PKA-mediated changes in sodium/glucose cotransport have been described in vivo and in vitro. In Chinese hamster ovary (CHO) cells overexpressing human SGLT1 and in rat small intestine, activation of PKA increased the number of SGLT1 in the membrane [32]. In oocytes expressing rabbit SGLT1, 8-Br-cAMP increased sodium/glucose cotransport capacity by nearly $30 \%$, an effect speculated to be caused by changes in SGLT1 trafficking [30]. Forskolin and 8-Br-cAMP were found to increase SGLT1 activity, a consequence of 
increased SGLT1 in the plasma membrane mediated by direct PKA-dependent phosphorylation [32]. In contrast, 8-Br-cAMP significantly reduced glucose uptake in human embryonic kidney cells transfected with human SGLT1 [33"]. In rats and sheep, when cAMP formation is stimulated by $\beta$-adrenergic agonists, intestinal SGLT1-mediated glucose uptake increases, an effect that can be inhibited by H-89, a PKA inhibitor [34,35].

PKC-mediated effects on SGLT1 have also been described. Surprisingly, vast species differences exist: PKC activation decreased the maximum transport capacity of rabbit and rat SGLT1, but was increased with human SGLT1 [30,36-38]. Some of these effects might depend on the coexpression of other proteins. For example, the expression of the regulatory protein RS1 differentially affected PKC-mediated glucose transport of human SGLT1. Stimulation of PKC without RS1 caused an increase in glucose transport, while in the presence of RS1, glucose transport was decreased [37]. RS1 knockout mice have a nearly seven-fold increase in intestinal SGLT1 [39], which is consistent with the finding that its presence inhibits SGLT1 expression [37,40]. The regulation of SGLT1 via PKC may require the activation of a complex signaling cascade involving $\mathrm{p} 38 /$ mitogen-activated protein kinase (MAPK), extracellular signal-regulated kinase (ERK)/MAPK, c-Jun N-terminal protein kinase (JNK)/MAPK and phosphoinositide-3 kinase (PI3K)/Akt/mammalian target of rapamycin (mTOR) [36,41-43]. There is some evidence that JAK2 activation might consecutively activate these signaling pathways [44]. A novel regulator of SGLT1 is tautubulin-kinase 2 (TTBK2), a serine/threonine kinase. In oocytes coex-pressed with TTBK2 and SGLT1, electrogenic glucose transport was increased compared with oocytes expressing kinase inactive mutants [45].

\section{Regulation by leptin}

Leptin, an adipocyte-derived hormone, is critically involved in energy intake and expenditure [46] and plays a role in intestinal nutrient absorption [47-49]. Intestinal SGLT1 expression does not require leptin because leptin-deficient mice have normal SGLT1 expression; however, hyperleptinemic mice [50] or leptin administration to rats [51] severely reduced SGLT1. Thus, leptin may play a role in regulating SGLT1 expression. Luminal leptin was able to acutely inhibit sodium-dependent glucose transport and reduce brush border membrane SGLT1 protein levels in genetically obese fa/fa rats [51]. In addition, intestine-specific deletion of the leptin receptor isoform $b$ resulted in downregulation of SGLT1 and a delayed onset of obesity [52]. Our own studies identified that intestinal SGLT1 expression and membrane abundance are severely reduced in hyperleptinemic $\mathrm{db} / \mathrm{db}$ mice [50]. The signaling pathways for leptin-induced SGLT1 regulation remain elusive but might include leptin-induced activation of both PKA and PKC as described in rat enterocytes $[51,53]$.

\section{Regulation by other signaling pathways}

The 'with-no-K[Lys] kinases'/STE20/SPS1-related proline/alanine-rich kinase (SPAK)/ oxidative stress responsive (OSR) kinase-1 pathway is a regulator of ion transport. Studies in oocytes and mice identified that SPAK is a powerful negative regulator of SGLT1.

Decreased glucose transport is due to SPAK-induced inhibition of SGLT1 insertion into the cell membrane [54"]. Studies on the role of OSR1 for the regulation of SGLT1 are more 
indirect: the glucose-induced current was lower in knockin mice carrying one allele of WNK-resistant OSR1 than wild-type mice [55].

The AMP-activated protein kinase (AMPK) is activated upon increased cytosolic AMP/ATP concentration ratio and thus senses the energy status of the cell. By studying catalytically inactive or constitutively active AMPK coexpressed with SGLT1 in oocytes, it was shown that active AMPK increased maximal sodium-dependent glucose transport by up to nearly $60 \%$ [56]. Related to the cellular stress response, SGLT1 activity is also enhanced by the serum and glucocorticoid-inducible kinase 1 and 3 (SGK1 and SGK3, respectively). SGK1 and SGK3 are not constitutively active and require activation via phosphoinositidedependent kinase-1 [57] or phosphatidylinositol-3-phosphate-5-kinase [58]. Although knockout of SGK1 had no effect on intestinal SGLT1 activity and expression [59], knockout of SGK3 caused a moderate decrease of intestinal SGLT1 activity [60]. Further, the coexpression of Nedd4-2, a ubiquitin ligase that is phosphorylated by SGK1 and SGK3, with SGLT1 caused a decrease in glucose current and cell surface expression [61].

\section{REGULATION OF SODIUM-GLUCOSE COTRANSPORTER 2}

Data on the regulation of SGLT2 are not as abundant as for the regulation of SGLT1. It is possible that SGLT2 is regulated at the transcriptional level by factors such as hepatocyte nuclear factor (HNF-1a), which can bind to the SGLT2 promotor region [30]. In addition, a recent phosphoproteomic analysis identified three novel phosphorylation sites in rat SGLT2 [62], providing evidence that in addition to SGLT1, SGLT2 might also be regulated via phosphorylation.

Studies in human embryonic kidney cells expressing human SGLT2 showed that activation of PKA and PKC increased glucose uptake by 225 and 150\%, respectively [33"]. PKAmediated glucose uptake might relate to an increased rate of vesicle fusion with the membrane; however, no such mechanism was found after PKC activation. SGLT2 gene sequence alignment identified that rat serine 623 was conserved and corresponded to human serine 624. Interestingly, expression of a serine 624 alanine mutant in rats prevented PKA and PKC stimulation of glucose uptake [33"]. The same mutation in human SGLT2 prevented an insulin-induced increase in glucose uptake. There is also evidence that oxidative stress mediates insulin-induced increases in SGLT2 expression in human proximal tubular cells [63"]. In contrast, no effect of insulin was observed on human SGLT1 [33"]. Studies in primary rabbit proximal tubule cultures also showed SGLT2 regulation via PKA, in addition to regulation by exchange proteins directly activated by cAMP (Epac), MAPK, nuclear factor $\mathrm{\kappa B}$ and caveolin-1. Although SGLT2 expression was increased following activation of Epac/PKA via ERK/p38, MAPK and nuclear factor $\kappa \mathrm{B}$, trafficking of SGLT2 to the plasma membrane requires caveolin-1 and F-actin $\left[33^{-}, 64\right]$.

In the kidney pig cell line (LLC-PK1), treatment with the cytokines interleukin 6 and tumor necrosis factor $a$ increased SGLT2 mRNA and protein expression compared with untreated cells [65]. Similarly, phosphorylation of the cytokine transforming growth factor $\beta 1$ and the downstream transcription factor smad3 increased SGLT2 protein expression in human kidney proximal tubular cells [66]. Under pathological conditions, both cobalt chloride and 
low oxygen pressure induced hypoxia in LLC-PK1 cells increased hypoxia-inducible factor-1a expression and was associated with reduced SGLT1 and SGLT2 expression [67"]. The mechanism remains elusive, but might involve reducing the work load under hypoxic conditions or could be an effect secondary to reduced sodium/potassium-ATPase activity.

Exposure to cadmium at toxicological levels causes glucosuria [68]. Cadmium exposure decreases sodium-dependent glucose uptake in primary cultures of mouse kidney cells that are paralleled by a decrease in the mRNA levels of SGLT1 and SGLT2, possibly mediated by cadmium interacting with the zinc finger domain of the transcription factor SP1 [69].

\section{RENAL SODIUM-GLUCOSE COTRANSPORTER REGULATION IN DIABETES}

Our own data support that there are opposing changes on renal SGLT2 expression depending on the diabetic model used (e.g. genetic vs. chemical). Studies in mice showed that streptozotocin (STZ, chemical)-induced type 1 diabetes mellitus (T1DM) significantly decreased renal SGLT2 expression [70]. This might relate to a toxic effect of STZ in the kidney [71], perhaps via changes in membrane lipid composition [72], an effect that was not described for SGLT1 [71]. In contrast, in STZ-induced diabetic rats, intestinal glucose transport and SGLT1 protein expression were increased [73]. The reason for these discrepancies remains elusive. In genetic diabetic models, including hyperleptinemic $\mathrm{db} / \mathrm{db}$ mice (type 2 diabetes mellitus, T2DM) and Akita mice (T1DM), we showed that renal SGLT2 expression was increased by 100 and 50\%, respectively [70]. The signaling pathways causing downregulation of SGLT1 in situations in which SGLT2 is absent [14"] or inhibited [74"'] remain to be determined; however, this might be a protective mechanism to save the S3 segment from glucose overload. For other factors regulating renal SGLT under diabetic conditions, including, but not limited to, the effect of diabetes on hyperplasia and hypertrophy, readers are referred to other excellent reviews $[1,2,75,76]$.

Due to the critical role of SGLTs in glucose homeostasis, there has been an increasing interest in developing SGLT1 and SGLT2 inhibitors as potential treatments for human disease. Selective SGLT2 inhibitors can target renal handling of glucose without the undesirable effects in other tissues in which SGLT1 mediates glucose and galactose absorption [1]. Dapagliflozin was the first selective SGLT2 inhibitor to be approved for treatment of T2DM in 2012 [1]. It was followed by the approval of other SGLT2 inhibitors such as canagliflozin, empagliflozin, ipragliflozin, tofogliflozin and luseogliflozin. These SGLT2-specific inhibitors increase urinary glucose excretion, lower blood glucose levels and may reduce blood pressure in T2DM patients [43,45-47]. Administration of the dual SGLT1/2 inhibitor, LX4211, to T2DM patients might be beneficial because SGLT2 inhibitors have shown limited efficacy in patients with moderate to severe renal impairment [77"-]. This problem might be overcome with SGLT1/2 inhibitors when SGLT1 inhibition causes delayed intestinal glucose absorption [44]. Although SGLT2 inhibitors are not approved for T1DM patients, there is evidence that they also may be helpful. In the Akita mouse model, empagliflozin attenuated/prevented hyperglycemia, glomerular hyperfiltration, hypertension and kidney growth [74"']. In particular, reduced early diabetic hyperfiltration and reduced kidney growth are of great interest, as it may be linked to the 
development of diabetic nephropathy $[8,39]$. These data are also supported by clinical trials showing that SGLT2 inhibitors efficiently lower blood glucose levels in T1DM patients [78].

Although most of the focus has been on SGLT2 inhibitors, SGLT1 inhibitors have also been shown to be effective at maintaining glucose homeostasis. Diabetic rats treated with a selective SGLT1 inhibitor reduced small intestinal glucose absorption, improved postprandial hyperglycemia, increased GLP-1 plasma levels and preserved glucosestimulated insulin secretion [79].

\section{CONCLUSION}

Over the last three decades, scientists have become aware of the key role of SGLT transport in diabetes and obesity, as evidenced by a tremendous increase in the number of yearly publications. These have contributed to the first step into the clinical era of the usage of SGLT inhibitors. Thus, future studies will provide an improved understanding of both beneficial and adverse effects of the clinical application of SGLT2-specific inhibitors. SGLT1-specific inhibitors may have a therapeutic potential. However, SGLT1 is, in contrast to SGLT2, expressed in various tissues including the heart, liver and lung [13"']. Thus, the effect of SGLT1 inhibition in these tissues should be of concern and this issue needs to be addressed with caution. This obstacle could potentially be overcome by the development of nonabsorbable SGLT1 inhibitors; however, diarrhea as a possible adverse effect needs to be considered. Although there is ample research on role of SGLT1/SGLT2 for glucose transport, more basic research is needed focusing on the molecular and biochemical regulation of SGLTs.

\section{Acknowledgments}

We thank Dr Jessica Dominguez Rieg for critically reading the manuscript.

Financial support and sponsorship

This work was supported by the Diabetes Endocrinology Research Center P30DK063491 (to T.R.), American Heart Association 15BGIA22410018 (to T.R.), Satellite Healthcare, a not-for-profit renal care provider (to T.R.) and the Department of Veterans Affairs. Further funding (to R.A. Fenton) is provided by the Lundbeck Foundation, the Danish Medical Research Council and the Novo Nordisk Foundation.

\section{REFERENCES AND RECOMMENDED READING}

1. Vallon V. The mechanisms and therapeutic potential of SGLT2 inhibitors in diabetes mellitus. Annu Rev Med. 2015; 66:255-270. Epub ahead of print. DOI: 10.1146/annurev-med-051013-110046 [PubMed: 25341005]

2. Gallo LA, Wright EM, Vallon V. Probing SGLT2 as a therapeutic target for diabetes: basic physiology and consequences. Diabetes Vasc Dis Re. 2015; 12:78-89.

3". Gorboulev V, Schurmann A, Vallon V, et al. Na+-D-glucose cotransporter SGLT1 is pivotal for intestinal glucose-absorption and glucose-dependent incretin secretion. Diabetes. 2012; 61:187196. This study is first that described the phenotype of the SGLT1 knockout mouse. [PubMed: 22124465]

4-m. Rieg T, Masuda T, Gerasimova M, et al. Increase in SGLT1-mediated trans-port explains renal glucose reabsorption during genetic and pharmacological SGLT2 inhibition in euglycemia. Am J Physiol Renal Physiol. 2014; 306:F188-F193. This study described renal glucose handling in SGLT1/SGLT2 double knockout mice. [PubMed: 24226519] 
5. Wright EM, Loo DDF, Hirayama BA. Biology of human sodium glucose transporters. Physiol Rev. 2011; 91:733-794. [PubMed: 21527736]

6. Dyer J, Merediz EFC, Salmon KSH, et al. Molecular characterisation of carbohydrate digestion and absorption in equine small intestine. Equine Vet J. 2002; 34:349-358. [PubMed: 12117106]

7. Zhao FQ, Zheng YC, Wall EH, McFadden TB. Cloning and expression of bovine sodium/glucose cotransporters. J Dairy Sci. 2005; 88:182-194. [PubMed: 15591382]

8. Herrmann J, Schroder B, Klinger S, et al. Segmental diversity of electrogenic glucose transport characteristics in the small intestines of weaned pigs. Comp Biochem Physiol A Mol Integr Physiol. 2012; 163:161-169. [PubMed: 22683689]

9. Batchelor DJ, Al-Rammahi M, Moran AW, et al. Sodium/glucose cotransporter-1, sweet receptor, and disaccharidase expression in the intestine of the domestic dog and cat: two species of different dietary habit. Am J Physiol Regul Integr Comp Physiol. 2011; 300:R67-R75. [PubMed: 20980625]

10. Muscher-Banse AS, Piechotta M, Schrooder B, Breves G. Modulation of intestinal glucose transport in response to reduced nitrogen supply in young goats. J Animal Sci. 2012; 90:49955004.

11. Moran AW, Al-Rammahi M, Zhang C, et al. Sweet taste receptor expression in ruminant intestine and its activation by artificial sweeteners to regulate glucose absorption. J Dairy Sci. 2014; 97:4955-4972. [PubMed: 24881785]

12. Yang CB, Albin DM, Wang ZR, et al. Apical $\mathrm{Na}^{+}$-D-glucose cotransporter 1 (SGLT1) activity and protein abundance are expressed along the jejunal crypt-villus axis in the neonatal pig. Am $\mathrm{J}$ Physiol Gastrointest Liver Physiol. 2011; 300:G60-G70. [PubMed: 21030609]

13m. Vrhovac I, Balen Eror D, Klessen D, et al. Localizations of $\mathrm{Na}^{+}$-d-glucose cotransporters SGLT1 and SGLT2 in human kidney and of SGLT1 in human small intestine, liver, lung, and heart. Pflügers Arch. 2014; Epub ahead of print. This study uses thoroughly evaluated SGLT1 and SGLT2 antibodies to characterize their expression in human tissue. doi: 10.1007/ s00424-014-1619-7

14. Vallon V, Platt KA, Cunard R, et al. SGLT2 mediates glucose reabsorption in the early proximal tubule. J Am Soc Nephrol. 2011; 22:104-112. This study first described the phenotype of the SGLT2 knockout mouse. [PubMed: 20616166]

15. Vallon V, Thomson SC. Renal function in diabetic disease models: the tubular system in the pathophysiology of the diabetic kidney. Annu Rev Physiol. 2012; 74:351-375. [PubMed: 22335797]

16. Ferraris RP, Diamond J. Regulation of intestinal sugar transport. Physiol Rev. 1997; 77:257-302. [PubMed: 9016304]

17. Dyer J, Hosie KB, Shirazi-Beechey SP. Nutrient regulation of human intestinal sugar transporter (SGLT1) expression. Gut. 1997; 41:56-59. [PubMed: 9274472]

18. Shirazi-Beechey SP, Gribble SM, Wood IS, et al. Dietary-regulation of the intestinal sodiumdependent glucose cotransporter (SGLT1). Biochem Soc Trans. 1994; 22:655-658. [PubMed: 7821657]

19. Ferraris RP, Vinnakota RR. Intestinal nutrient transport in genetically obese mice. Am J Clin Nutr. 1995; 62:540-546. [PubMed: 7661115]

20. Fisher RB, Gardner ML. A diurnal rhythm in the absorption of glucose and water by isolated rat small intestine. J Physiol. 1976; 254:821-825. [PubMed: 943523]

21. Corpe CP, Burant CF. Hexose transporter expression in rat small intestine: effect of diet on diurnal variations. Am J Physiol Gastrointest Liver Physiol. 1996; 271:G211-G216.

22. Tavakkolizadeh A, Berger UV, Shen KR, et al. Diurnal rhythmicity in intestinal SGLT-1 function, V-max, and mRNA expression topography. Am J Physiol Gastrointest Liver Physiol. 2001; 280:G209-G215. [PubMed: 11208542]

23. Pan XY, Terada T, Okuda M, Inui KI. The diurnal rhythm of the intestinal transporters SGLT1 and PEPT1 is regulated by the feeding conditions in rats. J Nutr. 2004; 134:2211-2215. [PubMed: 15333706]

24. Pan X, Hussain MM. Clock is important for food and circadian regulation of macronutrient absorption in mice. J Lipid Res. 2009; 50:1800-1813. [PubMed: 19387090] 
25. Mate A, Barfull A, Hermosa AM, et al. Regulation of sodium-glucose cotransporter SGLT1 in the intestine of hypertensive rats. Am J Physiol Regul Integr Comp Physiol. 2006; 291:R760-767. [PubMed: 16690767]

26". Grefner NM, Gromova LV, Gruzdkov AA, Komissarchik I. The interaction between SGLT1 or GLUT2 glucose transporter and the cytoskeleton in the enterocyte as well as Caco2 cell during hexose absorption. Tsitologiia. 2014; 56:749-757. This work suggested colocalization of the SGLT1 and GLUT2 and actin, as well as actin and a-tubulin, which suggests that elements of the cytoskeleton participate in the translocation of glucose transporters to the apical cell membrane. [PubMed: 25711084]

27. Ikari A, Harada H, Takagi K. Role of actin in the cAMP-dependent activation of sodium/glucose cotransporter in renal epithelial cells. Biochim Biophys Acta Biomemb. 2005; 1711:20-24.

28. Elvira B, Honisch S, Almilaji A, et al. Up-regulation of $\mathrm{Na}^{+}$-coupled glucose transporter SGLT1 by caveolin-1. Biochim Biophys Acta Biomemb. 2013; 1828:2394-2398.

29. Zhuang Z, Marshansky V, Breton S, Brown D. Is caveolin involved in normal proximal tubule function? Presence in model PT systems but absence in situ. Am J Physiol Renal Physiol. 2011; 300:F199-F206. [PubMed: 20980408]

30. Hirsch JR, Loo DDF, Wright EM. Regulation of $\mathrm{Na}^{+} /$glucose cotransporter expression by protein kinases in Xenopus laevis oocytes. J Biol Chem. 1996; 271:14740-14746. [PubMed: 8663046]

31. Wright EM, Hirsch JR, Loo DDF, Zampighi GA. Regulation of $\mathrm{Na}^{+} /$glucose cotransporters. J Exp Biol. 1997; 200:287-293. [PubMed: 9050236]

32. Subramanian S, Glitz P, Kipp H, et al. Protein kinase-A affects sorting and conformation of the sodium-dependent glucose co-transporter SGLT1. J Cell Biochem. 2009; 106:444-452. [PubMed: 19115253]

33-. Ghezzi C, Wright EM. Regulation of the human $\mathrm{Na}^{+}$-dependent glucose cotransporter hSGLT2. Am J Physiol Cell Physiol. 2012; 303:C348-C354. One of the limited studies describing the regulation of human SGLT2. [PubMed: 22673616]

34. Aschenbach JR, Borau T, Gabel G. Glucose uptake via SGLT-1 is stimulated by beta(2)adrenoceptors in the ruminal epithelium of sheep. J Nutr. 2002; 132:1254-1257. [PubMed: 12042442]

35. Ishikawa Y, Eguchi T, Ishida H. Mechanism of beta-adrenergic agonist-induced transmural transport of glucose in rat small intestine: regulation of phosphorylation of SGLT1 controls the function. Biochim Biophys Acta. 1997; 1357:306-318. [PubMed: 9268055]

36. Castaneda-Sceppa C, Subramanian S, Castaneda F. Protein kinase C mediated intracellular signaling pathways are involved in the regulation of sodium-dependent glucose co-transporter SGLT1 activity. J Cell Biochem. 2010; 109:1109-1117. [PubMed: 20069550]

37. Veyhl M, Wagner CA, Gorboulev V, et al. Downregulation of the $\mathrm{Na}^{+}$-D-glucose cotransporter SGLT1 by protein RS1 (RSC1A1) is dependent on dynamin and protein kinase C. J Memb Biol. 2003; 196:71-81.

38. Vayro S, Silverman M. PKC regulates turnover rate of rabbit intestinal $\mathrm{Na}^{+}$-glucose transporter expressed in COS-7 cells. Am J Physiol Cell Physiol. 1999; 276:C1053-C1060.

39. Osswald C, Baumgarten K, Stumpel F, et al. Mice without the regulator gene Rsc1A1 exhibit increased $\mathrm{Na}^{+}$-(D)-glucose cotransport in small intestine and develop obesity. Mol Cell Biol. 2005; 25:78-87. [PubMed: 15601832]

40. Reinhardt J, Veyhl M, Wagner K, et al. Cloning and characterization of the transport modifier RS1 from rabbit which was previously assumed to be specific for $\mathrm{Na}^{+}$-D-glucose cotransport. Biochim Biophys Acta. 1999; 1417:131-143. [PubMed: 10076042]

41. Pakladok T, Hosseinzadeh Z, Alesutan I, Lang F. Stimulation of the $\mathrm{Na}^{+}$-coupled glucose transporter SGLT1 by B-RAF. Biochem Biophys Res Commun. 2012; 427:689-693. [PubMed: 23010278]

42. Rexhepaj R, Artunc F, Metzger M, et al. PI3-kinase-dependent electrogenic intestinal transport of glucose and amino acids. Pflugers Arch. 2007; 453:863-870. [PubMed: 17051390]

43. Kempe DS, Siraskar G, Frohlich H, et al. Regulation of renal tubular glucose reabsorption by Akt2/PKB beta. Am J Physiol Renal Physiol. 2010; 298:F1113-F1117. [PubMed: 20164156] 
44. Hosseinzadeh Z, Bhavsar SK, Shojaiefard M, et al. Stimulation of the glucose carrier SGLT1 by JAK2. Biochem Biophys Res Commun. 2011; 408:208-213. [PubMed: 21406183]

45. Alesutan I, Sopjani M, Dermaku-Sopjani M, et al. Upregulation of $\mathrm{Na}^{+}$-coupled glucose transporter SGLT1 by Tau tubulin kinase 2. Cell Physiol Biochem. 2012; 30:458-465. [PubMed: 22814243]

46. Lee GH, Proenca R, Montez JM, et al. Abnormal splicing of the leptin receptor in diabetic mice. Nature. 1996; 379:632-635. [PubMed: 8628397]

47. Lostao MP, Urdaneta E, Martinez-Anso E, et al. Presence of leptin receptors in rat small intestine and leptin effect on sugar absorption. FEBS Lett. 1998; 423:302-306. [PubMed: 9515728]

48. Yarandi SS, Hebbar G, Sauer CG, et al. Diverse roles of leptin in the gastrointestinal tract: modulation of motility, absorption, growth, and inflammation. Nutrition. 2011; 27:269-275. [PubMed: 20947298]

49. Cammisotto PG, Levy E, Bukowiecki LJ, Bendayan M. Cross-talk between adipose and gastric leptins for the control of food intake and energy metabolism. Progr Histochem Cytochem. 2010; 45:143-200.

50. Dominguez Rieg JD, Chirasani V, Koepsell H, et al. Regulation of intestinal SGLT1 by catestatin in hyperleptinemic type 2 diabetic mice. FASEB J. 2015; 29:A970.9.

51. Ducroc R, Guilmeau S, Akashi K, et al. Luminal leptin induces rapid inhibition of active intestinal absorption of glucose mediated by sodium-glucose co-transporter 1. Diabetes. 2005; 54:348-354. [PubMed: 15677491]

52. Tavernier A, Cavin JB, Le Gall M, et al. Intestinal deletion of leptin signaling alters activity of nutrient transporters and delayed the onset of obesity in mice. FASEB J. 2014; 28:4100-4110. [PubMed: 24928195]

53. Barrenetxe J, Sainz N, Barber A, Lostao MP. Involvement of PKC and PKA in the inhibitory effect of leptin on intestinal galactose absorption. Biochem Biophys Res Commun. 2004; 317:717-721. [PubMed: 15081399]

54. Elvira B, Blecua M, Luo D, et al. SPAK-sensitive regulation of glucose transporter SGLT1. J Memb Biol. 2014; 247:1191-1197. This study reports that in oocytes, coexpression of SPAK and SGLT1 decreases SGLT1 plasma membrane abundance.

55. Pasham V, Pathare G, Fajol A, et al. OSR1-sensitive small intestinal $\mathrm{Na}^{+}$transport. Am J Physiol Gastrointest Liver Physiol. 2012; 303:G1212-G1219. [PubMed: 23019198]

56. Sopjani M, Bhavsar SK, Fraser S, et al. Regulation of $\mathrm{Na}^{+}$-coupled glucose carrier SGLT1 by AMP-activated protein kinase. Mol Memb Biol. 2010; 27:137-144.

57. Artunc F, Rexhepaj R, Volkl H, et al. Impaired intestinal and renal glucose transport in PDK-1 hypomorphic mice. Am J Physiol Regul Integr Comp Physiol. 2006; 291:R1533-R1538. [PubMed: 16741145]

58. Shojaiefard M, Strutz-Seebohm N, Tavare JM, et al. Regulation of the $\mathrm{Na}^{+}$, glucose cotransporter by PIKfyve and the serum and glucocorticoid inducible kinase SGK1. Biochem Biophys Res Commun. 2007; 359:843-847. [PubMed: 17570343]

59. Grahammer F, Henke G, Sandu C, et al. Intestinal function of gene-targeted mice lacking serumand glucocorticoid-inducible kinase 1. Am J Physiol Gastrointest Liver Physiol. 2006; 290:G1114-G1123. [PubMed: 16410368]

60. Sandu C, Rexhepaj R, Grahammer F, et al. Decreased intestinal glucose transport in the sgk3knockout mouse. Pflugers Arch. 2005; 451:437-444. [PubMed: 15971077]

61. Dieter M, Palmada M, Rajamanickam J, et al. Regulation of glucose transporter SGLT1 by ubiquitin ligase Nedd4-2 and kinases SGK1, SGK3, and PKB. Obesity Res. 2004; 12:862-870.

62. Feric M, Zhao B, Hoffert JD, et al. Large-scale phosphoproteomic analysis of membrane proteins in renal proximal and distal tubule. Am J Physiol Cell Physiol. 2011; 300:C755-C770. [PubMed: 21209370]

63. Nakamura N, Matsui T, Ishibashi Y, Yamagishi S. Insulin stimulates SGLT2-mediated tubular glucose absorption via oxidative stress generation. Diabetol Metab Syndr. 2015; 7:48. This study demonstrates that insulin stimulates SGLT2-mediated glucose entry into cultured proximal tubular cells via oxidative stress generation. [PubMed: 26023321] 
64. Lee YJ, Kim MO, Ryu JM, Han HJ. Regulation of SGLT expression and localization through Epac/PKA-dependent caveolin-1 and F-actin activation in renal proximal tubule cells. Biochim Biophys Acta Mol Cell Res. 2012; 1823:971-982.

65. Maldonado-Cervantes MI, Galicia OG, Moreno-Jaime B, et al. Autocrine modulation of glucose transporter SGLT2 by IL-6 and TNF-alpha in LLC-PK1 cells. J Physiol Biochem. 2012; 68:411420. [PubMed: 22351116]

66. Panchapakesan U, Pegg K, Gross S, et al. Effects of SGLT2 inhibition in human kidney proximal tubular cells-renoprotection in diabetic nephropathy? PLos One. 2013; 8:e54442. [PubMed: 23390498]

67-. Zapata-Morales JR, Galicia-Cruz OG, Franco M, Morales FMY. Hypoxia-inducible factor-1 alpha (HIF-1 alpha) protein diminishes sodium glucose transport 1 (SGLT1) and SGLT2 protein expression in renal epithelial tubular cells (LLC-PK1) under hypoxia. J Biol Chem. 2014; 289:346-357. In this work, it was shown that HIF-1a mediates changes in mRNA and protein expression of SGLT1 and SGLT2 in LLC-PK1 cell monolayers under low $\mathrm{O}_{2}$ concentrations. [PubMed: 24196951]

68. Tabatabai NM, Blumenthal SS, Lewand DL, Petering DH. Mouse kidney expresses mRNA of four highly related sodium-glucose cotransporters: regulation by cadmium. Kidney Int. 2003; 64:13201330. [PubMed: 12969150]

69. Kothinti RK, Blodgett AB, Petering DH, Tabatabai NM. Cadmium down-regulation of kidney Sp1 binding to mouse SGLT1 and SGLT2 gene promoters: possible reaction of cadmium with the zinc finger domain of Sp1. Toxicol Appl Pharmacol. 2010; 244:254-262. [PubMed: 20060848]

70. Vallon V, Rose M, Gerasimova M, et al. Knockout of Na-glucose transporter SGLT2 attenuates hyperglycemia and glomerular hyperfiltration but not kidney growth or injury in diabetes mellitus. Am J Physiol Renal Physiol. 2013; 304:F156-F167. [PubMed: 23152292]

71. Brouwers B, Pruniau VP, Cauwelier EJ, et al. Phlorizin pretreatment reduces acute renal toxicity in a mouse model for diabetic nephropathy. J Biol Chem. 2013; 288:27200-27207. [PubMed: 23940028]

72. Albertoni Borghese MF, Majowicz MP, Ortiz MC, et al. Expression and activity of SGLT2 in diabetes induced by streptozotocin: relationship with the lipid environment. Nephron Physiol. 2009; 112:45-52.

73. Debnam ES, Smith MW, Sharp PA, et al. The effects of streptozotocin diabetes on sodium-glucose transporter (SGLT1) expression and function in rat jejunal and ileal villus-attached enterocytes. Pflugers Arch. 1995; 430:151-159. [PubMed: 7675626]

74-. Vallon V, Gerasimova M, Rose MA, et al. SGLT2 inhibitor empagliflozin reduces renal growth and albuminuria in proportion to hyperglycemia and prevents glomerular hyperfiltration in diabetic Akita mice. Am J Physiol Renal Physiol. 2014; 306:F194-F204. This study uses the Akita mouse model of type 1 diabetes mellitus to evaluate the beneficial effects of empagliflozin. Results show that empagliflozin attenuates/prevents hyperglycemia, glomerular hyperfiltration, hypertension and kidney growth. [PubMed: 24226524]

75. Komala MG, Panchapakesan U, Pollock C, Mather A. Sodium glucose cotransporter 2 and the diabetic kidney. Curr Opin Nephrol Hypertens. 2013; 22:113-119. [PubMed: 23042029]

76. Vallon V. The proximal tubule in the pathophysiology of the diabetic kidney. Am J Physiol Reg I. 2011; 300:R1009-R1022.

77-. Zambrowicz B, Lapuerta P, Strumph P, et al. LX4211 therapy reduces postprandial glucose levels in patients with type 2 diabetes mellitus and renal impairment despite low urinary glucose excretion. Clin Ther. 2015; 37:71-82. This clinical trial shows that postprandial glucose levels were maintained in patients with an estimated GFR of less than $45 \mathrm{ml} / \mathrm{min} / 1.73 \mathrm{~m}^{2}$ despite the expected reduction in urinary glucose excretion suggesting that dual SGLT1/2 inhibition could prove useful for the treatment of patients with type 2 diabetes mellitus and impaired renal function. [PubMed: 25529979]

78. Henry RR, Rosenstock J, Edelman S, et al. Exploring the potential of the SGLT2 inhibitor dapagliflozin in type 1 diabetes: a randomized, double-blind, placebo-controlled pilot study. Diabetes Care. 2015; 38:412-419. [PubMed: 25271207] 
79. Shibazaki T, Tomae M, Ishikawa-Takemura Y, et al. KGA-2727, a novel selective inhibitor of a high-affinity sodium glucose cotransporter (SGLT1), exhibits antidiabetic efficacy in rodent models. J Pharmacol Exp Ther. 2012; 342:288-296. [PubMed: 22537769] 